\title{
Rebuilding better and fairer in the Eastern Mediterranean Region - the 68th session of the WHO Regional Committee
}

Ahmed Al-Mandhari

${ }^{1}$ Regional Director, World Health Organization Regional Office for the Eastern Mediterranean, Cairo, Egypt (Correspondence to: Ahmed Al-Mandhari: almandharia@who.int).

Citation: Al-Mandhari A. Rebuilding better and fairer in the Eastern Mediterranean Region - the 68th session of the WHO Regional Committee. East Mediterr Health J. 2021;27(10):945-946. https://doi.org/10.26719/2021.27.10.945

Copyright (C) World Health Organization (WHO) 2021. Open Access. Some rights reserved. This work is available under the CC BY-NC-SA 3.0 IGO license (https://creativecommons.org/licenses/by-nc-sa/3.o/igo).

The COVID-19 pandemic remains a major concern in the Eastern Mediterranean Region. At time of writing, nearly 300000 deaths from the disease have been reported (1), and that figure almost certainly understates the reality. The Region is facing another wave of infection; the Delta variant is widespread; and while some countries have achieved impressively high vaccination rates, overall coverage in the Region is far too low at around 15\% (2). Ensuring equitable access to COVID-19 vaccine across all 22 countries and territories in the Region is an urgent priority.

But the Region also has many other urgent health challenges, including addressing other health emergencies, combating both communicable and noncommunicable diseases, and promoting healthier populations, and we cannot wait for the pandemic to end before we tackle them. That was the main message of the 68th session of the WHO Regional Committee for the Eastern Mediterranean, WHO's governing body for the Region, which brought Member States and other stakeholders together from 11 to 14 October 2021 to discuss key health-related issues, share experiences and formulate ways forward. Continuing disruption to travel and risk from the pandemic obliged us to hold the session as a virtual event for the second year running, and while we certainly missed the opportunities for added interaction and the energy that an in-person session brings, it was still possible to accomplish a huge amount of business through four intensive days of online meetings.

The theme for this year's Regional Committee session was "Rebuilding better and fairer: stronger systems, resilient communities", and Member States agreed to a range of proposals to help ensure that the Region emerges both better and fairer from the pandemic. Many of those proposals drew on lessons learned dealing with the pandemic. The COVID-19 response has provided an unwelcome but nonetheless useful opportunity to review and enhance many aspects of WHO's work, most obviously our ability to manage large-scale emergencies, and that experience informed a new plan of action to accelerate health emergency preparedness and response in the Region which aims both to end the current pandemic and leave countries better prepared for future emergencies (3). Among many provisions, the resolution adopting the plan of action urged Member States to work for greater equity in COVID-19 vaccination in the Region through financial donations to the COVAX Facility and direct donations of vaccines by richer countries (4).

There was also important progress on the key issue of disease surveillance with the adoption of a regional strategy to encourage and support the integration of surveillance systems both within countries and within WHO (5), and Member States also considered broader lessons from the pandemic. In the latter regard, mindful of the value of community engagement in helping to ensure compliance with public health and social measures and combat misinformation about COVID-19, they expressed strong support for a new roadmap on building resilient communities for better health and well-being in the Region (6).

Meanwhile, other health priorities were not neglected. In particular, there were notable developments in efforts to tackle noncommunicable diseases and their associated risk factors. Diabetes is now more prevalent in the Eastern Mediterranean than in any other WHO region: 55 million (12.8\%) of the adult population aged $20-79$ had diabetes in 2019, and that figure is projected to rise to 108 million by 2045 if effective action is not taken (7). To enable a systematic response in every country, Member States adopted a new regional framework for action setting out a spectrum of strategic interventions covering governance, prevention, management, surveillance and research, all supported by indicators for clear monitoring and evaluation. And Member States also agreed to establish a High-level Ministerial Group on the Control of Tobacco and Emerging Tobacco and Nicotine Products in the Region, to galvanize work in this crucial area (8).

The Regional Committee also considered several matters that had been referred by or related to WHO's global governing bodies, the World Health Assembly and the Executive Board. This included a rich discussion of five consultation questions from the Working Group on Sustainable Financing (WGSF) (9). The WGSF was established at the start of this year, prompted by concerns that WHO does not receive a high enough level of unearmarked funds to fulfil its mandate, and has been seeking feedback from all the regional committees on possible changes to funding arrangements. While most stakeholders agree that current financing leaves WHO 
too dependent on donors and needs to change, there is as yet no consensus on exactly what form that change should take, and Member State comments in the Regional Committee session reflected diverse views. Sustainable financing is a critical prerequisite for WHO to achieve all its other goals, and we look forward to further fruitful discussion of this and other issues in 2022.

\section{References}

1. Eastern Mediterranean Regional Office COVID-19 Dashboard [website]. Cairo: WHO Regional Office for the Eastern Mediterranean; 2021 (https://app.powerbi.com/view?r=eyJrIjoiN2ExNWI3ZGQtZDk3MyooYzE2LWFjYmQtNGMwZjkoOWQ1MjFhIiwidCI6ImY2MTBjMGI3LWJkMjQtNGIzOSo4MTBiLTNkYzI4MGFmYjU5MCIsImMiOjh9, accessed 19 October, 2021).

2. Al-Mandhari, A. Introduction to the annual report of the Regional Director, Cairo, 12 October 2021 [speech]. Cairo: WHO Regional Office for the Eastern Mediterranean; 2021.

3. Accelerating health emergency preparedness and response - a plan of action. Cairo: WHO Regional Office for the Eastern Mediterranean; 2021 (EM/RC68/4; https://applications.emro.who.int/docs/EMRC684-eng.pdf?ua=1, accessed 19 October 2021).

4. Resolution EM/RC68/R.2. Accelerating health emergency preparedness and response - a plan of action. Cairo: WHO Regional Office for the Eastern Mediterranean; 2021.

5. A regional strategy for integrated disease surveillance - overcoming data fragmentation in the Eastern Mediterranean Region. Cairo: WHO Regional Office for the Eastern Mediterranean; 2021 (EM/RC68/5; https://applications.emro.who.int/docs/EMRC685-eng.pdf?ua=1, accessed 19 October 2021).

6. Building resilient communities for better health and well-being in the Eastern Mediterranean Region. Cairo: WHO Regional Office for the Eastern Mediterranean; 2021 (EM/RC68/6; https:/applications.emro.who.int/docs/EMRC686-eng.pdf?ua=1, accessed 19 October 2021).

7. Addressing diabetes as a public health challenge in the Eastern Mediterranean Region. Cairo: WHO Regional Office for the Eastern Mediterranean; 2021 (EM/RC68/7; https://applications.emro.who.int/docs/EMRC687-eng.pdf?ua=1, accessed 19 October 2021).

8. Resolution EM/RC68/R.1. Annual report of the Regional Director for 2020 Cairo: WHO Regional Office for the Eastern Mediterranean; 2021.

9. Meeting report of the Working Group on Sustainable Financing (Regional Committee version). Cairo: WHO Regional Office for the Eastern Mediterranean; 2021 (EM/RC68/9; https://applications.emro.who.int/docs/EMRC689-eng.pdf, accessed 19 October 2021). 